CUADERNOS DE ESTUDIOS GALLEGOS, LIX

Núm. 125 (enero-diciembre 2012), págs. 95-114

ISSN: 0210-847 X

DOI: 10.3989/ceg.2012.125.04

\title{
LOS PRIMEROS VIZCONDES DE ALTAMIRA EN LA VILLA DE VIVEIRO: ADQUISICIÓN Y PÉRDIDA DE UN SEÑORÍO EN EL REINO DE GALICIA*
}

\author{
Amparo Rubio Martínez \\ Instituto de Historia Simancas \\ Universidad de Valladolid
}

\begin{abstract}
* El presente artículo se inscribe en el marco del proyecto de investigación: "Linaje, parentela y poder: la pirámide nobiliaria gallega (siglos XIII al XV)" (I) Ref. HAR2010-18378 que se lleva a cabo en el Instituto de Estudios Gallegos "Padre Sarmiento", cuyo investigador principal es el Dr. Eduardo Pardo de Guevara y Valdés, y del subproyecto "Poder, sociedad y fiscalidad en el entorno geográfico de la Cornisa Cantábrica en el tránsito del Medievo a la Modernidad" Ref. HAR201127016-C02-01 integrado en el proyecto coordinado "Poder, sociedad y fiscalidad en la Corona de Castilla. Un estudio comparado de la meseta norte y de la cornisa cantábrica en el tránsito del medievo a la modernidad" Ref. HAR2011-27016-C02-00, financiados por el MINECO y desarrollados en el marco de la red temática de investigación cooperativa Arca Comunis. Abreviaturas utilizadas: AGS (Archivo General de Simancas), EMR (Escribanía Mayor de Rentas), RGS (Registro General del Sello), ARCHVa (Archivo Real Chancillería de Valladolid), RAH (Real Academia de la Historia).
\end{abstract}




\title{
LOS PRIMEROS VIZCONDES DE ALTAMIRA EN LA VILLA DE VIVEIRO: ADQUISICIÓN Y PÉRDIDA DE UN SEÑORÍO EN EL REINO DE GALICIA
}

\begin{abstract}
RESUMEN:
El presente artículo analiza la situación que atraviesa la villa de Viveiro en los años centrales del siglo $\mathrm{XV}$, especialmente en aquellos en los que aparece sujeta a la dependencia señorial de los primeros vizcondes de Altamira. En él se estudian cuestiones tan interesantes como la ocupación de la villa por el mariscal Pardo de Cela y las mercedes concedidas por Enrique IV al vizconde de Altamira para compensar la pérdida temporal del señorío. En el reinado de los Reyes Católicos, la villa de Viveiro recuperaba su condición realenga y la nueva política de mercedes puesta en marcha por los monarcas otorgaría amplios márgenes de poder al mayordomo real don Enrique Enríquez, nombrado desde los primeros años del reinado tenente de la villa.

Palabras ClaVE: Viveiro, siglo XV, Reyes Católicos, vizcondes de Altamira, Pardo de Cela.

\section{OS PRIMEIROS VIZCONDES DE ALTAMIRA NA VILA DE VIVEIRO: ADQUISICIÓN E PERDA DUN SEÑORÍO NO REINO DE GALICIA}

\begin{abstract}
Resumo:
O presente artigo analiza a situación que atravesa a vila de Viveiro nos anos centrais do século XV, especialmente naqueles nos que aparece suxeita á dependencia señorial dos primeiros vizcondes de Altamira. Nel estúdanse cuestións tan interesantes como a ocupación da vila polo mariscal Pardo de Cela e as mercedes concedidas por Enrique IV ao vizconde de Altamira para compensar a perda temporal do señorío. No reinado dos Reis Católicos, a vila de Viveiro recuperaba a súa condición realenga e a nova política de mercedes posta en marcha polos monarcas outorgaría amplos marxes de poder ao mordomo real don Enrique Enríquez, nomeado dende os primeiros anos do reinado tenente da vila.
\end{abstract}

Palabras Clave: Viveiro, século XV, Reis Católicos, vizcondes de Altamira, Pardo de Cela.

\section{THE FIRST VISCOUNTS OF ALTAMIRA IN VIVEIRO: ACQUISITION AND LOSS OF AN ESTATE IN THE KINGDOM OF GALICIA}

\begin{abstract}
:
This article analyzes the situation in the town of Viveiro in the middle years of the fifteenth century, especially in those where the subject appears stately dependence of the first Viscount of Altamira. It explores issues of interest such as the occupation of the town by Marshal Pardo de Cela and grants granted by Henry IV Viscount of Altamira to offset the temporary loss of the manor. In the reign of Ferdinand and Isabella, the town regained its status Viveiro realenga and Mercedes new policy launched by the monarchs would grant wide margins of power to royal butler Enrique Enriquez, named from the first years of the reign of tenente villa.
\end{abstract}

KEY WORDS: Viveiro, $15^{\text {th }}$ century, The Catholic Monarchs, Viscounts of Altamira, Pardo de Cela. 
Recibido/Received: 01/06/2012

Aceptado/Accepted: 14/08/2012

\section{INTRODUCCIÓN}

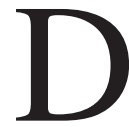

urante toda la Edad Media, la villa de Viveiro disfrutó de una posición privilegiada desde el punto de vista económico, en parte determinada por su situación estratégica, considerándose un punto de referencia clave en las relaciones comerciales que la corona de Castilla establecía con la fachada atlántica europea a media y larga distancia. Esto explica en cierto modo, las continuas mercedes y privilegios reales que los monarcas otorgaron a la villa desde mediados del siglo XIII, tratando de favorecer la actividad comercial que mantenía con otros puertos del norte peninsular y del Atlántico europeo. A esta situación geográfica privilegiada, se venía a añadir el notable volumen de ingresos que generaba la actividad comercial desarrollada en el puerto, derivada fundamentalmente de la entrada de productos por vía marítima -diezmos de la mar- y de la posibilidad con la que contaba de vender sal en los depósitos o almacenes reales, los denominados alfolíes de la sal. ${ }^{1}$ Su posición estratégica y su importancia económica constituirían sin duda motivos suficientes para que la corona tratara de mantenerla sujeta a su dependencia. ${ }^{2}$ Sin embargo, en

\footnotetext{
${ }^{1}$ Sobre la situación estratégica y posición que ocupa en las relaciones comerciales la villa de Viveiro véase Fernando López Alsina, Introducción al fenómeno urbano medieval gallego a través de tres ejemplos: Mondoñedo, Vivero y Ribadeo, Universidad de Santiago de Compostela, 1976, Elisa Ferreira Priegue, Galicia en el comercio marítimo medieval, La Coruña, 1988, "Galicia en la marisma de Castilla. La dinámica de los intercambios mercantiles" en Ciudades y villas portuarias del Atlántico en la Edad Media, Coord. B. Arízaga Bolúmburu y J.A. Solórzano Telechea, Nájera, 2005, págs. 165-186, "El comercio de las villas costeras de Galicia en la Baja Edad Media", El Museo de Pontevedra, ${ }^{\circ} 43$ (1989), págs. 247-264. Para muchos otros aspectos en relación con la historia de Viveiro véase José García Oro, Galicia en los siglos XIV y XV. 2 vols, Pontevedra, 1981, y José García Oro y Miguel Romaní, "Viveiro en el siglo XVI" Estudios Mindonienses, vol. 5 (1989), págs. 13-269.

${ }^{2}$ La primera noticia con la que contamos sobre la existencia de alfolí en la villa data de 1289 . Se trata de una carta de privilegio mediante la cual Sancho IV concedía facultad al obispo de Mondoñedo y a sus sucesores, para hacer salinas en los puertos de la diócesis. En 1338, el ordenamiento de Alfonso XI fijaba la existencia de alfolíes en el reino de Galicia en los puertos de Santa Marta de Ortigueira, La Coruña, Viveiro y Baiona, y ya a mediados del siglo XV, se constata la existencia de
} 
ocasiones los monarcas se vieron obligados a ceder estas villas y ciudades de realengo a ciertas familias, generalmente de la aristocracia, a las que en muchos casos trataron de compensar por los servicios prestados a la corona. Este fué el caso, por ejemplo, de Rodrigo de Villandrando, que en 1431 recibía la villa de Ribadeo con título de condado, o del contador de Juan II, Fernán Sánchez de Saldaña, que conseguía hacerse con ciertos señoríos próximos a Salamanca, además de otras propiedades, oficios públicos remunerados y numerosas rentas de la corona, y del mismísimo Alonso Pérez de Vivero, notario y contador mayor de Juan II, que en 1451 recibía la villa de Viveiro con los diezmos de la mar y alfolíes a cambio de ciertas villas que poco después pasarían a formar parte del señorío de Villena. ${ }^{3}$

Las páginas que siguen a continuación centran la atención en un periodo muy concreto de la historia de Viveiro, que comprende los años en los que el linaje Vivero, se sitúa al frente del señorío de la villa, en especial aquellos que coinciden con la ocupación del mariscal Pardo de Cela. Desde que en 1451 fuera cedida a Alonso Pérez de Vivero, hasta su reversión a la corona en 1465, la villa se ve envuelta en una serie de acontecimientos turbulentos, en especial en los años en los que aparece ocupada por Pardo de Cela (1465-1478). Apartada la figura del primer vizconde de Altamira y del mariscal de la villa de Viveiro, y proclamada su condición realenga en 1477, los monarcas ordenaban la confiscación de una parte de los bienes del II vizconde de Altamira, recuperando la villa y sus rentas para la corona. Desde 1480 en adelante, los monarcas confiarían la villa de Vi-

alfolí propio en los puertos de Tui, Baiona de Miño, Pontevedra, Padrón, Noia, Muros, A Coruña, Betanzos y Navia. Es posible, no obstante que durante estos años se hubiesen autorizado otros puntos de venta cercanos, teniendo en cuenta que durante el reinado de los Reyes Católicos, tenemos noticia del pago de derechos de alfolíes en otros puertos del reino de Galicia. En el caso de Viveiro, es evidente que la villa debió mantener el privilegio de poseer alfolí propio durante todo el siglo $\mathrm{XV}$, a pesar de que las rentas del mismo hubieran sido cedidas en 1451 al contador Alonso Pérez de Vivero. Sobre éstas concesiones véase Juan Donapétry IRIBARNEGARAY, "Privilegios, cédulas y cartas reales otorgadas a Vivero", Boletín de la Comisión Provincial de Monumentos de Lugo, ${ }^{\circ}$ 40 (1953), pág. 239 y Miguel Ángel Ladero Quesada, La Hacienda Real de Castilla en el siglo XV, La Laguna, 1973, pág. 179.

${ }^{3}$ Sobre la cesión de la villa de Ribadeo a los Villandrando véase José Manuel CALDERÓN ORTEGA, "La formación del señorío castellano y el mayorazgo de Rodrigo de Villandrando, conde de Ribadeo (1439-1448) Anuario de Estudios Medievales, 16, 1986, págs. 421-447. Un completo estudio sobre la carrera política y trayectoria profesional del contador Fernán Sánchez de Saldaña en Alfonso de Ceballos-Escalera y Gila, "Generación y Semblanza de Fernán López de Saldaña, contador mayor de Juan II de Castilla", Medievalismo, 21, (2011), págs. 161-206. Un caso semejante, el del contador Sancho García de Villalpando, estudiado por Ana Isabel CARRASCo MANChado, "Dos clérigos en una familia de oficiales reales: notas sobre Francisco y Antonio García de Villalpando", Anuario de Estudios Medievales, 35/2 (2005), págs. 605-633. 
veiro al mayordomo real don Enrique Enríquez, al que nombraban tenente de la fortaleza, encargándole también el control de las rentas de la villa.

\section{LA ADQUisición DEL SEÑORÍO POR El CONTADOR Alonso PÉREZ DE VIVERO.}

La figura del contador mayor de cuentas de Juan II, don Alonso Pérez de Vivero (+ 1453), desarrolla su carrera política durante la década de los años treinta y cuarenta del siglo XV, a la sombra de don Álvaro de Luna, valido de Juan II. Según apunta Alfonso Franco, Alonso Pérez era natural de la villa lucense de Viveiro, que algunos años después recibiría en señorío por merced real de Juan II. ${ }^{4}$

Poco es lo que conocemos acerca de sus orígenes, ascenso y carrera profesional desarrollada al servicio del condestable, si bien en 1439 desempeñaba el cargo de contador mayor de cuentas, una actividad que se le reconoce desde 1434. ${ }^{5}$ Es ya en la década de los años cincuenta cuando se le hacía merced del señorío de la villa de Viveiro, a partir de la permuta efectuada con el heredero de la corona, al pertenecer dicha villa, desde 1440, al señorío del príncipe de Asturias. Así, el 25 de marzo de 1451 el rey Juan II hacía merced a su hijo, el príncipe don Enrique, de la villa de Viveiro con su tierra, término y rentas anejas, a fin de que la pudiese permutar con el contador mayor, Alonso Pérez de Vivero. Y este mismo año, el príncipe heredero hacía merced al contador del señorío de la villa con las rentas de los diezmos de la mar y alfolíes, a cambio de las villas de Xorquera, Alcalá, Ves y La Roda, de las que éste último era titular. ${ }^{6}$ Efectuada la permuta, el príncipe don Enrique decidía otorgar estas villas al marqués de Villena, don Juan Pacheco, comprometiéndose junto a éste último a amparar y defender al contador mayor en la posesión y señorío de la villa de Viveiro.

Desde 1451 en adelante, Alonso Pérez de Vivero y sus descendientes, los primeros vizcondes de Altamira, se titularán señores de Viveiro y su tierra, un título que disfrutarán hasta el 15 de junio de 1465, fecha en la que perderían

\footnotetext{
${ }^{4}$ Al respecto señala Gonzalo CHACón en la Crónica de don Alvaro de Luna: "El rey lo fizo señor de la villa de Vibero, donde era su naturaleza" citado por Alfonso Franco SiLVA, "Alfonso Pérez de Vivero, contador mayor de Juan II de Castilla. Un traidor y su fortuna”, Hispania, n 165 (1987), pág. 86.

5 Miguel Ángel Ladero Quesada, La Hacienda Real de Castilla, La Laguna, 1973, pág. 20, citado por A. Franco Silva “Alfonso Pérez de Vivero, contador ..”, págs. 86-87.

${ }^{6}$ AGS, Mercedes y privilegios, leg 93, fol. 12: Carta de privilegio del rey Juan II a Alonso Pérez de Vivero, otorgada en Burgos, 20 de septiembre de 1451. Alfonso Franco Silva señala el año de 1447 como el momento en el que el contador mayor obtiene el señorío de Viveiro por merced regia. Sin embargo, la documentación consultada en el Archivo General de Simancas pone de manifiesto que este hecho tuvo lugar algunos años después, concretamente en 1451.
} 
el señorío de la villa y tierra como consecuencia de la ocupación del mariscal Pardo de Cela, que se había proclamado alcalde de la villa un año antes. ${ }^{7}$ Es indudable que durante el breve período de tiempo que estuvo al frente del señorío, el contador logró acrecentar el señorío, incorporando nuevos territorios y rentas, aunque algunos de ellos los había obtenido en años anteriores, como el señorío de Galdo, del que era titular desde 1435 a partir de la permuta efectuada con el obispo de Mondoñedo. ${ }^{8}$

La claúsula de mayorazgo en favor de su sucesor y primogénito, Juan de Vivero, hijo de su mujer legítima, doña Inés de Guzmán, nos permite precisar cuales eran los dominios señoriales que el contador mayor poseía en torno a la, hasta entonces realenga, villa de Viveiro, y que incluía la propia villa con su tierra y términos, las rentas de los diezmos de la mar y alfolíes de la sal, las feligresías de Galdo y Xuances, Santo Estevo do Vale, San Miguel das Negradas, las Ribeiras de Sor, los castillos de Vilaxoán y Samarugo con sus términos, vasallos y jurisdicciones, las Pueblas de Navia y Burón con sus correspondientes rentas, pechos y derechos. ${ }^{9}$

Sobre el patrimonio que poseía fuera del reino de Galicia contamos con algunas noticias acerca del mayorazgo que había fundado en Fuensaldaña, a lo que se venía a añadir algunos de sus dominios señoriales situados entre la ciudad de Zamora y la villa de Gema, además del cuantioso volumen de juros y mercedes que poseía en los principales partidos de la Corona de Castilla. ${ }^{10}$ Pocos años después de su muerte, su viuda, doña Inés de Guzmán Dávila, efectuaba la venta y permuta de ciertas villas y lugares, algunas de ellas situadas en el reino de Galicia. Concretamente, el 13 de enero de 1458, ya viuda del contador, vendía las

\footnotetext{
${ }^{7}$ Sobre la figura del contador mayor, Alonso Pérez de Vivero, véase José García Oro, Galicia en los siglos XIV y XV. Galicia urbana. Vol II, pág. 102, Enrique CAL PARDO, "Juan II, Alonso Pérez de Vivero y el señorío de Galdo", Compostelanum, 26, núms. 1-4 (1981), págs. 37-82, Alfonso Franco Silva, "Alfonso Pérez de Vivero, contador mayor de Juan II de Castilla. Un traidor y su fortuna" Hispania, no 165, 1987, págs. 83-116. Juan DonapeTry Iribarnegaray, Historia de Vivero y su concejo, Vivero, [s.n.], 1953, págs. 159-181.

${ }^{8}$ E. CAL PARDo, "Juan II, Alonso Pérez de Vivero y el señorío de Galdo...”, págs. 40-41. La permuta efectuada entre el obispo de Mondoñedo, D. Pedro Enríquez de Castro, y el contador Alonso Pérez de Vivero había tenido lugar el 13 de abril de 1435. Noticia de la confirmación de la reina Juana de un juro de heredad de 5.000 mrs. que el contador mayor Alonso Pérez de Vivero había otorgado al obispo de Mondoñedo a cambio del señorío de Galdo (Burgos, 20 de junio de 1508) en Juan Donapetry Iribarnegaray, "Privilegios, cédulas y cartas reales otorgadas a Vivero" Boletín de la Comisión Provincial de Monumentos de Lugo, no 40 (1953), pág. 243.

${ }^{9}$ AGS, EMR, Mercedes y Privilegios, leg 93, fol 26: Se trata del traslado de una claúsula de mayorazgo fechada en Valladolid a 6 de octubre de 1484. Un extracto de la carta de mayorazgo original, otorgada el 19 de diciembre de 1452 por el contador Alonso Pérez de Vivero en favor de su primogénito Juan de Vivero, en RAH, Colección Salazar y Castro, M-9, fols. 230r-232v.

${ }^{10}$ RAH, Col. Salazar y Castro, M-52, fols. 18v-38v.
} 
pueblas de Navia y Burón a Pedro Osorio, I conde de Lemos, y sólo cuatro meses después, llevaba a cabo la permuta de la villa de Belmonte de Campos, por las villas de Cangas y Tineo, que habían pertenecido a don Juan Manuel. Este mismo año, suscribía también una escritura de compromiso con don Enrique de Acuña sobre la propiedad de Villalba del Alcor. ${ }^{11}$

\section{La PResencia de Pardo de Cela en la villa y la Reintegración deL SEÑORÍO A LA CORONA.}

Durante los años centrales del reinado de Enrique IV, coincidiendo con la titularidad del I vizconde de Altamira al frente del señorío de Viveiro, la figura del mariscal Pedro Pardo de Cela hace su aparición en tierras de Mondoñedo donde actuará como encomendero durante algo más de una década. Por lo que se refiere a la aparición y posterior permanencia de Pardo de Cela en la villa de Viveiro, cabe suponer que dicha aparición podría responder a una estrategia planteada desde la monarquía con el fin de lograr la reversión de la villa a la Corona. Contribuye a reforzar nuestra hipótesis el hecho de que, desde mediados de los años sesenta, hasta los primeros años de la década siguiente, el mariscal protagonizara numerosos abusos en tierras del obispado de Mondoñedo mediante la ocupación y usurpación de la mayor parte de las rentas de un gran número de beneficios eclesiásticos, sin que tengamos indicio de castigo alguno por parte de la Corona. De este modo, todo parece indicar que Enrique IV pudo haber facilitado al mariscal la entrada en la villa, compensando con numerosas mercedes al primer vizconde de Altamira, que por este motivo, quedaba apartado temporalmente del señorío. $^{12}$

Los años centrales de la década de los sesenta fueron cruciales en lo que a la concesión de rentas reales se refiere, en medio de un clima de conflicto y guerra civil que enfrentó al rey Enrique IV con su hermanastro, el príncipe don

\footnotetext{
${ }^{11}$ RAH, Col. Salazar y Castro, M-92, fols. 154-156, M-1, fols.239-239v, leg 5, car. 4.

${ }^{12}$ Entre los trabajos más recientes sobre la figura del mariscal cabe mencionar los presentados a las Primeras Xornadas de Estudios Medievais da Mariña Central. O Mariscal Pardo de Cela e o seu tempo, celebradas entre los días 4 y 7 de diciembre de 2004, en el castillo del Castro de Ouro (Alfoz). En especial destacan los trabajos de Eduardo PARDo de Guevara Y VALdÉs, "El mariscal Pardo de Cela: leyenda, mito y realidad", págs. 1-51 y César Olivera Serano, "Galicia en la política de los Reyes Católicos", págs. 413-440. Algunos trabajos antiguos y bien conocidos sobre la figura del mariscal son los de Eduardo Lence Santar, El mariscal Pardo de Cela y la Santa Hermandad, Mondoñedo, Acción Social Católica, 1930, Francisco MaYán Fernández, El mariscal Pardo de Cela a la luz de la nueva documentación histórica, Vivero, [s.n.], 1962, José Villaamil y Castro, "El mariscal Pardo de Cela" Galicia Histórica, 2 (1901), págs. 83-98, 3 (1901), págs. 146-163. Eduardo Pardo de Guevara y Valdés, El mariscal Pardo de Cela y la Galicia del siglo XV, Lugo, Alvarellos, 1981, y del mismo autor "Los Pardo de Cela del siglo XV. Documentos Medievales", Anuario Brigantino, 9 (1986), págs. 23-30.
} 
Alfonso. En este contexto tendría lugar la concesión de mercedes a buena parte de la nobleza castellana, tratando de procurarse su favor político. Entre esta nueva nobleza que había logrado hacer fortuna a partir del desempeño de cargos y oficios en la corte, se encontraba el vizconde de Altamira, Juan de Vivero, que durante estos años había logrado consolidar un notable señorío en torno a la villa de Valladolid y su término.

Es precisamente a principios de los años sesenta, cuando recién proclamado alcalde de la villa, el mariscal Pardo de Cela desplazaba del señorío al vizconde de Altamira, Juan de Vivero. ${ }^{13}$ Ante los daños y perjuicios causados por el mariscal, Enrique IV no dudaría en compensar al vizconde con determinadas ayudas y mercedes. Así, el 29 de marzo de 1465, le hacía merced de 450.000 mrs. de juro de heredad y 934 quintales situados en los diezmos del aceite de Sevilla. ${ }^{14}$

De la cantidad mencionada, un total de 150.000 mrs. le habían sido concedidos en enmienda y remuneración de las rentas de Viveiro, que pertenecientes a su mayorazgo, habían sido embargadas como consecuencia de la toma y ocupación de la villa por el mariscal. La cantidad restante, hasta completar el total, la obtenía el vizconde a partir de otros dos privilegios, el primero de ellos de 100.000 mrs. de juro de heredad por su oficio de contador mayor de cuentas, y el segundo, otorgado ya en 1471, de 200.000 mrs. en compensación de los daños que le hubiera podido ocasionar la ocupación de la villa por Pardo de Cela, con la única condición de que dicha cantidad fuese restituida a la Hacienda Regia una vez que el vizconde hubiese recuperado la villa. ${ }^{15}$ Algunos años después, en

${ }^{13}$ La presencia de Pardo de Cela en la villa de Viveiro ha sido bien estudiada por José García Oro, "Viveiro y la familia de los Pardo de Cela" Estudios Mindonienses, vol. 4 (1988), págs. 151-232.

14 AGS, EMR, Mercedes y Privilegios, leg 93, fol 26.

15 RAH, Colección Salazar y Castro, K-85, fols. 76v-78: Por privilegio de Enrique IV otorgado el 29 de marzo de 1465, el vizconde de Altamira, Juan de Vivero, obtenía los primeros 150.000 mrs. de juro de heredad en enmienda y compensación de las rentas de la villa de Viveiro, que perteneciente a su mayorazgo, se hallaban embargadas al haber sido tomada y ocupada la villa por el mariscal. Dicha cantidad quedaría situada en ciertas rentas de la villa de Valladolid (50.000), Palencia (60.000), Becerril (21.000) y en las alcabalas de ciertos lugares de la merindad de Campos (19.000). Además de la cantidad mencionada, Juan de Vivero obtenía otros 100.000 mrs. de juro de heredad por su cargo de Contador Mayor de Cuentas al servicio de Enrique IV, una cantidad que debería quedar situada en las alcabalas de Jerez de la Frontera y su partido (25.000), aceite de Sevilla (15.000), alcabalas y tercias de la merindad de Campos con Palencia (25.000) y en las alcabalas de la merindad de Cerrato (20.000). Por último, mediante carta de privilegio otorgada el 31 de agosto de 1471, Enrique IV le hacía merced de 200.000 mrs. de juro de heredad por el empeño de la villa de Viveiro, hasta que dicha villa le fuese restituída. De esta cantidad, 160.000 se hallaban situados en las rentas del reino de Galicia: en las alcabalas de la ciudad de Santiago y villas y lugares de su arzobispado con La Coruña (45.000), en las alcabalas de Betanzos (25.000), en los diezmos y alfolíes (30.000), en las alcabalas del obispado de Mondoñedo con Vilamaior y sus cotos y feligresías (40.000), en las alcabalas de Lugo con sus cotos y feligresías y en las villas y lugares de su obispado 
tiempos de los Reyes Católicos, buena parte de los juros y mercedes, señorío y bienes patrimoniales que Juan de Vivero había logrado consolidar en torno a la villa de Valladolid, serían confiscados a su primogénito, Alonso Pérez de Vivero, II vizconde de Altamira. ${ }^{16}$

Este clima de conflicto y guerra civil explica también el hecho de que el monarca concediera las primeras mercedes al de Altamira en marzo de 1465, que poco después le apartara del señorío como castigo a la fidelidad prestada a la causa del príncipe don Alfonso, del que se había proclamado contador mayor en 1467, y que de nuevo, en 1471, le compensara con otros $200.000 \mathrm{mrs}$. por los daños ocasionados por la ocupación de la villa por Pardo de Cela. ${ }^{17}$ Sin embargo, durante estos años, coincidiendo con la ocupación de Pardo de Cela en Viveiro, ya se puede observar la clara intención por parte del monarca de recuperar la villa para la Corona Real. Buena prueba de ello es la decisión de Enrique IV en 1465 de incorporarla al realengo, una idea en la que se reafirmaría pocos meses después, cuando ordenaba decididamente la desvinculación de Viveiro de la casa de Altamira, alegando los graves delitos que Juan de Vivero había cometido contra la Corona Real, revocando por ello la donación que, algunos años antes, Juan II había concedido a su padre, el contador Alonso Pérez de Vivero.

Un año después, era la propia villa de Viveiro la que solicitaba la confirmación de la orden anterior, quedando Juan de Vivero desplazado del señorío. ${ }^{18}$ Esta decidida voluntad por apartar al vizconde de Altamira de la villa de Viveiro, constituye ya un claro precedente de la decisión que los Reyes Católicos tomarían algunos años después, cuando decidían apartar al vizconde del señorío de la villa con carácter definitivo. Pero por otra parte, la idea de los reyes de recuperar la condición realenga de Viveiro, se integra dentro del proceso general de reafirmación de la autoridad real y recuperación de las ciudades y villas de realengo del reino de Galicia, entre las que se encontraban Betanzos, Baiona, La Coruña y Viveiro, por su posición estratégica y por el considerable volumen de ingresos que procuraban sus rentas para la Hacienda Regia.

La estrategia planteada por la monarquía para apartar al vizconde de Altamira de Viveiro no se haría esperar, legitimando en cierto modo la ocupación y presencia continuada de Pardo de Cela en la villa, mediante la concesión de nuevas mercedes y juros de heredad. Es posible que con este fin, el monarca hubiese

(20.000). Los 40.000 mrs. restantes hasta completar el total de 200.000 mrs., se situaban en las alcabalas de Écija (30.000) y en las de León con su obispado (10.000).

16 AGS, RGS, Vitoria, 5 de diciembre de 1483, fol 209.

17 J. García Oro, "Viveiro y la familia de los Pardo de Cela", pág. 155.

18 Juan Donapetry Iribarnegaray, "Privilegios, cédulas y cartas reales otorgadas a Vivero", Boletín de la comisión de monumentos de Lugo, nº 40 (1953), págs. 242. 
ordenado en 1466 la sustitución de los 40.000 mrs. que Pardo de Cela percibía en concepto de acostamiento por su contribución con 20 lanzas al servicio de la monarquía, por un juro de heredad de idéntico valor a percibir sobre las alcabalas de ciertos lugares del obispado de Mondoñedo, algunos de ellos muy próximos a la villa de Viveiro. ${ }^{19}$ Algunos años después, concretamente desde el año 1473 en adelante, se constata también la percepción por parte del mariscal de un total de $50.000 \mathrm{mrs}$. de juro de heredad situados sobre las alcabalas de ciertos lugares y feligresías del obispado de Mondoñedo a partir de la renunciación que en su favor había efectuado el vizconde de Altamira, Juan de Vivero, quien a su vez los había obtenido de su hermano, Gil de Vivero. ${ }^{20}$ En relación con este último juro, es curioso el hecho de que, desplazados los vizcondes de Altamira de Viveiro por el mariscal Pardo de Cela a mediados de los años sesenta, sólo ocho años después fuese precisamente Juan de Vivero quien renunciase esta notable cantidad en su favor, de lo que se deduce, una vez más una clara intención por parte de la corona de facilitar a Pardo de Cela la ocupación de la villa como medio de incorporarla al realengo poco después.

Es evidente que estas mercedes que el mariscal fue consiguiendo sobre las rentas reales le habrían permitido un mayor control del territorio y desde luego, una excusa inmejorable para prolongar su presencia en la villa. A partir de aquí, cabe pensar que el mariscal se habría tomado excesivas atribuciones sobre la villa de Viveiro, sobre todo cuando, recién proclamada su condición realenga en 1465, ésta había intentado sumarse a la hermandad, obteniendo el rechazo inmediato de algunos señores, entre ellos del mariscal. Sobre esta cuestión, en enero de 1470, el monarca ordenaba contener los abusos de cualquier caballero o persona poderosa en defensa y amparo de los derechos de la villa. ${ }^{21}$

Con posterioridad a esta fecha, el monarca trataría de preservar la condición realenga de la villa de Viveiro de cualquier amenaza, defendiéndola de todo

${ }^{19}$ Entre estos lugares se encontraban las feligresías de Grallal y Suegos (1.000), Landrove (2.000) y La Marina de Viveiro (5.000). Al respecto véase AGS, EMR, Mercedes y Privilegios, leg11, fol. 152 y leg 91, fols. 56 y 70: Albalá de Enrique IV (17 de mayo de 1466), Carta de privilegio por la que se conceden a Pardo de Cela 40.000 mrs. de juro de heredad a percibir sobre las rentas reales de Mondoñedo y su obispalía (Valladolid, 25 de septiembre de 1466), Carta de privilegio y confirmación de estos 40.000 mrs. de juro (Segovia, 22 de octubre de 1466) y carta de privilegio y confirmación de los Reyes Católicos confirmando los privilegios anteriores (Segovia, 14 de febrero de 1476). La noticia también en J. Donapetry Iribarnegaray, "Privilegios, cédulas y cartas reales...", pág. 242

20 AGS, EMR, Mercedes y privilegios, leg 91, fol. 70: Carta de renunciación de Juan de Vivero, en favor del mariscal Pedro Pardo de Cela otorgada en Altamira, 19 de mayo de 1473. Carta de privilegio de Enrique IV, mediante la cual hace merced al mariscal Pardo de Cela de $50.000 \mathrm{mrs}$. de juro de heredad con cargo a las alcabalas del obispado de Mondoñedo (27 de mayo de 1473).

21 J. DonaPeTRy Iribarnegaray, “Privilegios, cédulas y cartas reales...”, pág. 242. 
abuso, y evitando cualquier ocupación que, prolongada en el tiempo, pudiese poner en peligro su condición jurídica. El objetivo sería entonces la figura del mariscal, que desde finales de los años sesenta había cometido numerosos abusos y extorsiones en tierras del obispado de Mondoñedo. En este sentido, en 1470 el monarca extendía una primera provisión real mediante la cual prohibía terminantemente la edificación de casas fuertes en la villa de Viveiro, así como toda extorsión o daño que pudiera causar cualquier caballero o persona poderosa a los habitantes de la villa. El monarca prohibía también la constitución de juntas para tomar la villa y daba orden expresa de que no se acogiesen en ella personas poderosas sin licencia real. ${ }^{22}$

Durante los primeros años de su reinado, los Reyes Católicos aún mantuvieron una estrecha relación con el mariscal, el cual, recién proclamada reina Isabel en diciembre de 1474, prestaba juramento de fidelidad como justicia y gobernador de la villa de Viveiro, lo que seguramente le habría granjeado la confirmación por parte de los reyes del privilegio otorgado por Enrique IV el 17 de marzo de $1466 .^{23}$

Sin embargo, los últimos años de la década de los setenta serían decisivos en la vida del mariscal. La ocupación de tierras del obispo de Mondoñedo, así como de numerosos beneficios eclesiásticos y ciertas heredades de señorío laico y la toma indebida de sus rentas, le acarrearían serios problemas que darían lugar a numerosas quejas de particulares a la Corona.

La documentación del Registro General del Sello de Simancas contiene abundantes noticias acerca de los abusos cometidos por el mariscal Pardo de Cela en tierras del obispado de Mondoñedo durante estos años. Baste recordar tan sólo algunos capítulos como el que se refiere a la ocupación de ciertos bienes pertenecientes a la familia Vivero, o las quejas que en 1480 presentaban los arcedianos de Neira y Tineo, como titulares de los beneficios de Galdo y Magaz, que habían sido tomados ilícitamente por el mariscal, llevando los frutos y rentas derivados de dichos beneficios. Y este mismo año, tenían lugar también las quejas presentadas por los mercaderes vizcaínos Martín de Mijancas y Pedro de Arriaga, a los que un criado del mariscal, había tomado ciertas mercaderías en el puerto de Viveiro por valor de unas 3.000 doblas. ${ }^{24}$ La respuesta por parte de la Corona ante tales abusos no se haría esperar, de manera que el 26 de junio

\footnotetext{
22 Ibid, pág. 242.

23 Ibid, págs. 242- 243.

24 AGS, RGS, Sevilla, 14 de junio de 1478, fol. 21, Toledo, 30 de mayo de 1480, fol. 82, Medina del Campo, 25 de octubre, 1480, fol. 124. Una copia del testamento del mariscal en ARChVa, PL CIVILES, Alonso Rodríguez (F), Caja 2595, 1
} 
de 1478, los monarcas prohibían la entrada en Viveiro al mariscal, ordenándole expresamente abandonar la villa mientras no contase con licencia real. ${ }^{25}$

En septiembre de 1478, tenemos noticia por primera vez del enfrentamiento abierto que Pardo de Cela mantenía con los oficiales reales, especialmente con el corregidor de Viveiro, Fernando de Cerón, a quien el rey Fernando había encargado la restitución de los lugares, cotos y tierras de Viveiro, que tenía entrados y tomados el mariscal. ${ }^{26}$ Dos años después, era el propio Pardo de Cela el que elevaba sus quejas a la justicia real, exponiendo los abusos y extorsiones que le estaba ocasionando Fernando de Cerón, que había usurpado buena parte del señorío jurisdiccional del obispado de Mondoñedo, prendiendo a algunos de sus vasallos, entre ellos a su criado Álvaro de Santa Marina, y cometiendo numerosos abusos en sus propias tierras. Ante las quejas expuestas, el monarca encargaba al gobernador Acuña informarse acerca de lo sucedido y administrar justicia en favor del mariscal. ${ }^{27}$

Los últimos años de la vida del mariscal se revelan especialmente complicados. Apartado definitivamente de Viveiro en 1478, los continuos enfrentamientos que mantuvo con los oficiales reales, en especial con el gobernador Acuña y el corregidor Fernando de Cerón, serían decisivos en su trágica muerte. En el caso particular de Cerón, cabe suponer que el enfrentamiento se habría desatado cuando, en cumplimiento de las órdenes reales encomendadas, trataba de recuperar los lugares, cotos y feligresías que el mariscal había tenido ocupados hasta la fecha. En este sentido, cabe recordar también que a finales de los años setenta, el corregidor Cerón trabajaba como criado al servicio del mayordomo real don Enrique Enríquez, al que los reyes habían tratado de ceder la villa de Viveiro en numerosas ocasiones, haciéndole merced, finalmente, de las rentas reales de la misma mediante el nombramiento de tenente de la fortaleza de la villa. De este modo, en 1478, Fernando de Cerón en su cargo de corregidor de la villa de Viveiro, pero sobre todo como criado del mayordomo real, se encargaría del arrendamiento y recaudación de las rentas de la villa y de eliminar la presencia del mariscal en Viveiro. Proclamada la condición realenga de la villa de Viveiro en 1477, y apartada la figura del mariscal en 1478, los monarcas iniciaban un proceso de confiscación de los bienes del II vizconde de Altamira, que tendría lugar a principios de los años ochenta. Todo ello constituía una garantía más de que la villa no sería nuevamente enajenada, a lo que los reyes se comprometían de nuevo en $1485 .^{28}$

\footnotetext{
${ }^{25}$ AGS, RGS, Sevilla, 26 de junio de 1478, fol. 111.

26 J. Donapetry IRIBarnegaray, "Privilegios, cédulas y cartas reales...", pág. 243

27 AGS, RGS, Medina del Campo, 11 de septiembre de 1480, fol. 209

28 J. Donapetry Iribarnegaray, "Privilegios, cédulas y cartas reales...”, pág. 243
} 


\section{LAS CARTAS DECLARATORIAS DE TOLEDO: CONFISCACIÓN DE BIENES Y} PÉRDIDA DEFINITIVA DEL SEÑORÍO DE LOS PRIMEROS VIZCONDES DE ALTAMIRA.

Al iniciarse el reinado de los Reyes Católicos, ocupaba la titularidad del señorío el segundo vizconde de Altamira, Alonso Pérez de Vivero, hijo de Juan de Vivero y de doña María de Acuña, y homónimo de su abuelo, el notario y contador de Juan II. Al titularse segundo vizconde de Altamira, Alonso Pérez de Vivero heredaba buena parte del patrimonio y rentas que su padre, Juan de Vivero, había obtenido a partir de distintas mercedes y privilegios de Enrique IV: los 450.000 mrs. de juro de heredad situados en los partidos de Sevilla, Jerez, Valladolid, Campos, Merindades y Galicia, 934 quintales en los diezmos del aceite del partido de Sevilla, más las rentas, pechos y derechos correspondientes a ciertas feligresías del obispado de Mondoñedo que serían confiscadas por los oficiales reales a principios de los años ochenta. El nuevo titular de la casa de Altamira disfrutaba de estas rentas en virtud del privilegio que Enrique IV había otorgado a su padre, Juan de Vivero, en enmienda de la villa de Viveiro y su tierra, que vinculada a su mayorazgo, había sido tomada y ocupada por el mariscal Pedro Pardo de Cela desde mediados de los años sesenta. El vizconde, Juan de Vivero, recibía esta merced con carácter indefinido, en tanto que recuperase el señorío de la villa de Viveiro. ${ }^{29}$ Se trataba en este caso de una de las mercedes más cuantiosas concedidas por Enrique IV a lo largo de su reinado, cuya concesión pudo tener una doble intencionalidad; por una parte procurarse el favor político de este acaudalado noble castellano y por otra compensarle por la pérdida temporal del señorío de Viveiro a raíz de la ocupación de Pardo de Cela.

A principios de los años ochenta, los Reyes Católicos ponían en marcha un proceso general de confiscación de los bienes del II vizconde de Altamira, Alonso Pérez de Vivero, como castigo a su adhesión al bando portugués en la guerra civil castellana, en la que había participado activamente, llegando a constituir compañía propia junto a Diego de Ribas, vecino de Fontíveros. ${ }^{30}$ A pesar de todo, los monarcas atendieron sus peticiones, especialmente las relativas al señorío de Viveiro, del que su padre había sido apartado en 1465 por orden expresa de Enrique IV.

Pasado el episodio de la guerra civil, en 1480 los Reyes Católicos firmaban las capitulaciones con Portugal otorgando las correspondientes cartas de perdón a los defensores de la causa portuguesa. ${ }^{31}$ Entre ellos se encontraba, por supuesto, el vizconde de Altamira, al que tres años antes, los reyes habían confirmado

\footnotetext{
${ }^{29}$ AGS, Mercedes y Privilegios, leg 93, fol 26.

${ }^{30}$ AGS, RGS, Trujillo, 6 de julio de 1479, fol. 41.

31 AGS, RGS, Toledo, 9 de junio de 1480, fol. 34.
} 
los 934 quintales de aceite en las rentas de Sevilla y los 450.000 mrs. de juro de heredad en distintos partidos de la corona de Castilla. ${ }^{32}$

Sin embargo, a pesar de la carta de perdón concedida al II vizconde de Altamira en 1480, las cartas declaratorias de Toledo afectarían de manera decisiva a los distintos juros y mercedes de los que era titular, quedando reducidos en una tercera parte de su valor. ${ }^{33}$ En 1480, las declaratorias de Toledo fijaban en 150.000 mrs. el juro de heredad que el vizconde de Altamira percibiría en lo sucesivo en las rentas de los partidos mencionados. ${ }^{34}$ En este sentido, conviene advertir que el nivel de reducción que experimentaron las mercedes del vizconde fue similar al aplicado a otros nobles y aristócratas castellanos, especialmente a aquellos que habían obtenido ciertas mercedes de manera irregular durante el último decenio del reinado de Enrique IV, como era el caso de Juan de Vivero. ${ }^{35}$

La política de confiscación de bienes llevada a cabo contra el vizconde de Altamira no se limitó a la reducción de juros y mercedes situados sobre las rentas reales, sino que a principios de los ochenta, se extendía también a algunos de sus dominios señoriales, en los que durante años, había recaudado un voluminoso conjunto de rentas, pechos y derechos. Entre estos lugares que en 1482 se confiscaban al vizconde de Altamira, la documentación hacendística hace referencia a ciertas feligresías que situadas en el obispado de Mondoñedo le habían sido entregadas en los años pasados. ${ }^{36}$ En líneas generales, es posible afirmar que el embargo de bienes decretado contra el vizconde de Altamira ponía de manifiesto, un claro interés por parte de la monarquía en recuperar buena parte de las rentas que, hasta la fecha, habían permanecido enajenadas.

Efectuada la confiscación de parte de sus bienes y hacienda, y firmadas las capitulaciones entre Castilla y Portugal, el vizconde de Altamira solicitaba la devolución de los mismos, calificando de injustas las medidas tomadas contra

\footnotetext{
32 AGS, Mercedes y Privilegios, leg 93, fol. 26: Confirmación de los Reyes Católicos de 23 de diciembre de 1477 .

${ }^{33}$ José García Oro, Galicia en los S. XIV y XV. Galicia señorial, vol I... op. cit., pág. 356.

${ }^{34}$ AGS, Diversos de Castilla, leg 5, fol 88 y Antonio Matilla Tascón, Declaratorias de los Reyes Católicos sobre reducción de juros y otras mercedes, Madrid, 1952, pp 234-235. De estos 150.000 mrs., 62.787 mrs., se situaban en los partidos de Valladolid (12.833), Palencia (34.954), Jerez (5.000) y Sevilla (10.000). Una parte considerable de este juro, 53.334 mrs., se hallaba situado en las rentas del reino de Galicia: en el arzobispado de Santiago (15.000 mrs.), Betanzos (8.334 mrs.), en las rentas de los diezmos de la mar y alfolíes del reino de Galicia (10.000 mrs.), en Mondoñedo y su obispalía (13.334 mrs). y en Lugo (6.666 mrs).

35 Sobre la reducción de juros y mercedes aplicada a la nobleza y aristocracia del reino de Galicia véase mi artículo, "Las cartas declaratorias de Toledo. La reducción de juros y mercedes aplicada a la nobleza y aristocracia gallega" Boletín de la Real Academia de la Historia, vol. 207 (2010), págs. 95-139.

${ }^{36}$ AGS, EMR, leg 32, fols. 58, 70, 71 y 154 y leg 33, fol. 52.
} 
él. Los argumentos del vizconde causarían efecto inmediato en la corte, de tal modo que el 5 de diciembre de 1483, los reyes ordenaban al gobernador Acuña levantar el secuestro de todos sus bienes y acudir a don Alonso Pérez de Vivero con todos los frutos y rentas que le perteneciesen, con excepción de las cantidades que estimase oportunas para el gasto de la tenencia de la fortaleza de Fuensaldaña y de 25.000 mrs. que los reyes habían mandado entregar a la vizcondesa doña Mencía para el mantenimiento de su nieta, la hija del vizconde don Alonso Pérez. ${ }^{37}$ El desembargo de estos bienes permitiría al vizconde recuperar una parte de los juros de heredad que percibía sobre las rentas reales, posiblemente, una parte de los diezmos de la mar y alfolíes de la villa de Viveiro que había recibido por herencia de su padre, Juan de Vivero, y de su abuelo y homónimo, Alonso Pérez de Vivero. Muy al contrario, las alcabalas de los dominios señoriales de Alonso Pérez de Vivero pasarían a formar parte de los ingresos habituales de la Hacienda Regia, sin posibilidad de que el vizconde pudiese recuperarlas.

Por otra parte, nos consta que la orden de desembargo de bienes y rentas confiscados al vizconde no se aplicó de manera efectiva a la totalidad de sus bienes, pues al menos la fortaleza de Vilaxoán continuaría en manos de los gobernadores reales hasta mediados de los años noventa. A principios de los ochenta, Alonso Pérez de Vivero había entregado esta fortaleza al gobernador Acuña, y poco después, aprovechando la estancia del gobernador en Castilla, la fortaleza había sido tomada por el caballero lucense Fernán Arias de Saavedra. Unos años después, el nuevo gobernador en el reino de Galicia, Diego López de Haro, conseguía cercar la fortaleza y entregarla de nuevo a la Corona, si bien, el 19 de junio de 1493, los reyes ordenaban su devolución al vizconde de Altamira, al haber sido secuestrada la fortaleza junto al resto de sus bienes en los años ochenta. ${ }^{38}$

El castigo y confiscación de bienes aplicado al II vizconde de Altamira corría parejo al proceso seguido por la corona contra la figura del mariscal, quien como ya se ha señalado, desde 1478 en adelante sufriría un acoso permanente por parte de los oficiales reales, y muy especialmente del corregidor de la villa de Viveiro, Fernando de Cerón.

Apartada la figura del mariscal de Viveiro y confiscada una parte de la hacienda y patrimonio del II vizconde de Altamira, la villa quedaba definitivamente vinculada a la Corona y sus rentas pasarían a engrosar el capítulo de ingresos que la Hacienda Real recaudaba en el obispado de Mondoñedo. Desde que en 1475 los reyes dieran cuenta de haber incorporado la villa de Viveiro al realen-

\footnotetext{
37 AGS, RGS, Vitoria, 5 de diciembre de 1483, fol 209.

${ }^{38}$ AGS, RGS, Barcelona, 19 de junio de 1493, fol 280. Sobre la intervención del gobernador Acuña en la fortaleza de Villaxoán confiscada al vizconde de Altamira, y tomada por la fuerza por Fernan Arias de Saavedra, tenemos noticia a través del pleito Tabera-Fonseca.
} 
go, las promesas de no enajenarla a persona alguna serían continuas. A pesar de todo, en 1480 hacían merced de la tenencia de Viveiro al mayordomo real don Enrique Enríquez, un cargo retribuido con una dotación anual de 250.000 mrs, a percibir en las rentas de la villa, lo que indudablemente, le permitía un gran margen de maniobra y actuación en la villa y su término.

\section{Las mercedes de los Reyes Católicos: El mayordomo Don EnRiQue ENRÍQUEZ Y LA TENENCIA DE LA VILLA DE VIVEIRO}

Tal y como hemos señalado en los apartados anteriores, a finales de los años setenta, la villa de Viveiro conseguía desvincularse definitivamente del señorío de los vizcondes de Altamira y de la presencia de Pardo de Cela, y al mismo tiempo los reyes adoptaban el compromiso de no enajenarla a persona alguna. ${ }^{39}$ Sin embargo, según se deduce de varios testimonios documentales, parece que ya a mediados de los años setenta existía una idea generalizada de que los reyes habían intentado cederla al mayordomo real, don Enrique Enríquez, tío del rey don Fernando. Por este motivo, el 25 de junio de 1476, el rey Fernando juraba no haber hecho merced de la villa a don Enrique Enríquez, señalando incluso como había llegado a cederla por merced a la propia villa. ${ }^{40}$

Esta promesa de no enajenar la villa sería ratificada por los propios monarcas en septiembre de este mismo año, si bien, poco después los reyes nombrarían tenente de la villa al mayordomo real, que desde 1480 en adelante, tendría pleno y absoluto control sobre la villa y sus rentas. El nombramiento de don Enrique Enríquez tenía lugar en un momento en el que la villa de Viveiro con sus cotos y feligresías se constituía como partido fiscal independiente. De este modo, la Hacienda Regia conseguía recuperar los ingresos derivados del arrendamiento de alcabalas, diezmos de la mar y alfolíes de la villa, que por estos años generaban beneficios muy notables. A fines del siglo $\mathrm{XV}$, eran precisamente los ingresos derivados del pago de los diezmos de la mar y alfolíes, los que generaban mayores beneficios, representando aproximadamente el $25 \%$ del total de las contribuciones ordinarias, una cifra por debajo de la cual se situaban otros ramos alcabalatorios fuertes desde el punto de vista económico como el pescado, con beneficios muy notables que se situaban en torno al $15 \%$, o el vino y la sal que aparecen representados cada uno de ellos en proporciones de algo más del 14\%. Por debajo de los ramos mencionados se situaban ya las alcabalas del "dozil", cueros y hierro, rapina, carnicería, heredades y pan en grano ${ }^{41}$.

\footnotetext{
39 J. Donapetry Iribarnegaray, "Privilegios, cédulas y cartas reales...”, págs. 242-243.

40 Ibid, pág. 243.

${ }^{41}$ AGS, Exp. de Hac., leg. 18, fol. 28.
} 
Desde finales de los años setenta, los monarcas confiaban la villa a la figura del mayordomo y a personajes vinculados a su entorno más inmediato. En 1478, era el corregidor de Viveiro y criado del mayordomo, Fernando de Cerón, el que se hacía cargo del arrendamiento y recaudación de las rentas de la villa y del mismo modo, en los años siguientes las rentas estarán a cargo de los criados y servidores del mayordomo real, entre los que se cuentan por ejemplo a Rodrigo de la Serna, Lope de Cieza, Rodrigo de Mendoza, Tomé Álvarez, Gonzalo de Mijancas, Lope de Urueña o Diego de Verdesoto.

Desde 1480 en adelante y casi hasta finales del reinado, el mayordomo don Enrique Enríquez recibiría la práctica totalidad de las rentas de la villa para el mantenimiento de la tenencia de Viveiro, así como para la retribución de su cargo de mayordomo real de ayudas de costa y acostamientos. Así por ejemplo, en 1490, obtenía el importe global de las rentas de Viveiro (266.750 mrs.) para el mantenimiento de la fortaleza de la villa (250.000 mrs.) y en concepto de ayuda de costa $(16.750 \mathrm{mrs} .)^{42}$.

Por consiguiente, aunque los reyes no alteraron la promesa de no enajenar la villa a ningún noble ni persona poderosa, en la práctica confiaron su control y administración de sus rentas al mayordomo real, permitiéndole un amplio margen de acción sobre ella. El mayordomo y sus servidores se situarán al frente de Viveiro hasta 1499, cuando los reyes le hacían merced de 377.000 mrs. de por vida como compensación a la entrega de la fortaleza de Viveiro a la Corona. La concesión de esta merced a don Enrique Enríquez, dejaba libres las rentas de Viveiro para hacer frente a otros gastos de la Corona. Así, desde 1499 en adelante, la práctica totalidad de las rentas de Viveiro sería entregada a los distintos tesoreros reales para atender el pago de las tropas de las guardas reales, una partida del gasto que por estos años se habían incrementado notablemente, al igual que la que se ocupaba de los gastos de la cámara real. Una proporción muy inferior era la que se dedicaba al mantenimiento de la fortaleza de la villa, a cuyo cargo se situaría, desde 1499, Alonso Ordóñez de Villaquirán.

\section{CONCLUSIONES}

A partir de las cuestiones analizadas en los capítulos precedentes y a modo de conclusión, conviene recordar algunos de los principales acontecimientos sucedidos en la villa de Viveiro en un período tan complejo de su historia como fue la segunda mitad del siglo XV. Tras una larga trayectoria vinculada al señorío del obispo de Mondoñedo, a principios del siglo XV, la villa de Viveiro conse-

\footnotetext{
42 AGS, EMR, leg. 47, fol. 314; leg. 48, fols. 117 y 304; leg. 49, fols. 185 y 186; leg. 50, fol. 70 ; y leg. 51 , fol. 54 (1490-91).
} 
guía adquirir la condición de realenga. Los privilegios otorgados a la villa por los primeros trastámara constituirían un factor de primer orden en la reducción que en lo sucesivo experimentaría la jurisdicción de la iglesia de Mondoñedo, facilitando además la entrada de oficiales reales en la villa que, progresivamente, se irían haciendo con el control del territorio.

Integrada en el principado de Asturias en los años cuarenta del siglo XV, el rey Juan II la cedía en 1451 al príncipe heredero, quien a su vez la otorgaría por merced regia al notario y contador mayor, Alonso Pérez de Vivero, que a cambio de la misma, hacía entrega de ciertas plazas estratégicas situadas en el marquesado de Villena. Tras la ocupación de la villa por el mariscal Pardo de Cela en los años sesenta y ante el intento de Enrique IV de proclamar la villa realenga en 1465 apartándola del señorío de los vizcondes de Altamira, el reinado de los Reyes Católicos venía a suponer la reincorporación definitiva de la villa a la corona. Así, en 1477 los reyes proclamaban su condición realenga, comprometiéndose a no enajenarla nunca más y a mantenerla sujeta a su dependencia.

La nueva política de mercedes emprendida por los Reyes Católicos beneficiaría especialmente al mayordomo real, don Enrique Enríquez, tío del rey, que durante casi todo el reinado tendría pleno control sobre la villa y sus rentas y que había delegado el gobierno de Viveiro en personas de su confianza, cuyos intereses venían a coincidir con los de determinados caballeros y personas poderosas que hasta el momento habían ejercido cierto control sobre la villa. Una vez más, se pone de manifiesto que la investigación a la luz de la documentación nos permite esclarecer algo más algunas cuestiones hasta ahora poco o nada conocidas y precisar mejor muchos aspectos en relación con los acontecimientos sucedidos en la villa de Viveiro durante la segunda mitad del siglo XV. En ésta línea, espero que continúen las investigaciones que acerca de los distintos linajes nobiliarios, oligarquías urbanas y élites de poder de la Galicia bajomedieval se han iniciado en los últimos años, especialmente en relación con la presencia y actuación en los núcleos urbanos del reino y con el gobierno y administración de las diferentes villas y ciudades del reino. 


\section{BIBLIOGRAFÍA}

Cal Pardo, Enrique, "Juan II de Castilla, Alonso Pérez de Vivero y el señorío de Galdo", Compostelanum, vol. 26, núms. 1-4 (1981), págs. 37-82.

Calderón Ortega, José Manuel, "La formación del señorío castellano y el mayorazgo de Rodrigo de Villandrando, conde de Ribadeo (1439-1448), Anuario de Estudios Medievales, vol. 16 (1986), págs. 421-447.

Carrasco Manchado, Ana Isabel, "Dos clérigos en una familia de oficiales reales: notas sobre Francisco y Antonio García de Villalpando", Anuario de Estudios Medievales, 35/2 (2005), págs. 605-633.

Ceballos-Escalera y Gila, Alfonso de, "Generación y semblanza de Fernán López de Saldaña, contador Mayor de Juan II de Castilla", Medievalismo, 21 (2011), págs. 161-206.

Donapetry Iribarnegaray, Juan, "Privilegios, cédulas y cartas reales otorgadas a Vivero", Boletín de la Comisión Provincial de Monumentos Históricos y Artísticos de Lugo, $\mathrm{n}^{\circ} 40$ (1953), págs. 237-253.

Donapetry Iribarnegaray, Juan, Historia de Vivero y su concejo, Vivero, [s.n.], 1953.

Ferreira Priegue, Elisa, Galicia en el comercio marítimo medieval, La Coruña, Fundación Pedro Barrié de la Maza, 1988 (Col. Documentos históricos).

Ferreira Priegue, Elisa, "El comercio de las villas costeras de Galicia en la Baja Edad Media", El Museo de Pontevedra, núm. 43 (1989), págs. 247-264.

Ferreira Priegue, Elisa "Galicia en la marisma de Castilla. La dinámica de los intercambios mercantiles" en B. Arízaga Bolúmburu y J.A. Solórzano Telechea (coords.), Ciudades y villas portuarias del Atlántico en la Edad Media, Nájera, Instituto de Estudios Riojanos, 2005, págs. 165-186 (Col. Actas).

Franco Silva, Alfonso, "Alfonso Pérez de Vivero, contador mayor de Juan II de Castilla. Un traidor y su fortuna”, Hispania, núm. 165 (1987), págs. 83-116.

García Oro, José y Romaní, Miguel, "Vivero en el siglo XVI", Estudios Mindonienses, vol. 5 (1989), págs. 13-269.

García Oro, José "Viveiro y la familia de los Pardo de Cela", Estudios Mindonienses, vol. 4 (1988), págs. 151-232.

García Oro, José, Galicia en los siglos XIV y XV, [La Coruña], Fundación Pedro Barrié de la Maza, 1987, 2 vols. (Col. Galicia Histórica).

Ladero Quesada, Miguel Ángel, La Hacienda Real de Castilla en el siglo XV, La Laguna, Universidad, 1973 (Estudios de historia, 1).

Lence Santar, Eduardo, El mariscal Pardo de Cela y la Santa Hermandad, Mondoñedo, Acción Social Católica, 1930.

López Alsina, Fernando, Introducción al fenómeno urbano medieval gallego a través de tres ejemplos: Mondoñedo, Vivero y Ribadeo, Santiago, Universidad de Santiago de Compostela, 1976.

Matilla Tascón, Antonio, Declaratorias de los Reyes Católicos sobre reducción de juros y otras mercedes, Madrid, Servicio de Estudios de la Inspección Gral. del Min. de Hacienda, 1952.

Mayán Fernández, Francisco El mariscal Pardo de Cela a la luz de la nueva documentación histórica, Vivero, [s.n.], 1962. 
Olivera Serrano, César, "Galicia en la política de los Reyes Católicos", en Manuel Alonso Valín Valdés, Carlos Andrés González Paz, Juan Ramón Fernández Pacios (coords.), $O$ Mariscal Pardo de Cela e o seu tempo: I Xornadas de Estudios Medievais da Mariña Central, [Lugo], Diputación Provincial de Lugo, 2006, págs. 413-440.

Pardo de Guevara y Valdés, Eduardo, El mariscal Pardo de Cela y la Galicia del siglo XV, Lugo, Alvarellos, 1981.

Pardo de Guevara y Valdés, Eduardo, "Documentos medievales: los Pardo de Cela del siglo XV”, Anuario Brigantino, 9 (1986), págs. 23-30.

Pardo de Guevara y Valdés, Eduardo, "El Mariscal Pardo de Cela. Una injusticia ejemplar", Torre de los Lujanes: Boletín de la Real Sociedad Económica Matritense de Amigos del País, 55 (2005), págs. 83-108.

Pardo de Guevara y Valdés, Eduardo, "El mariscal Pardo de Cela: leyenda, mito y realidad", en Manuel Alonso Valín Valdés, Carlos Andrés González Paz, Juan Ramón Fernández Pacios (coords.), O Mariscal Pardo de Cela e o seu tempo: I Xornadas de Estudios Medievais da Mariña Central, [Lugo], Diputación Provincial de Lugo, 2006, págs. 1-51.

Rubio Martínez, Amparo, "La Hacienda Real del reino de Galicia durante el reinado de Juan II (1406-1454), En la España Medieval, vol. 31 (2008), págs. 397-458.

Rubio Martínez, Amparo, "Las cartas declaratorias de Toledo. La reducción de juros y mercedes aplicada a la nobleza y aristocracia gallega", Boletín de la Real Academia de la Historia, vol. 207 (2010), págs. 95-139.

Villaamil y Castro, José "El mariscal Pardo de Cela", Galicia Histórica, 2 (1901), págs. 8398.

Villaamil y Castro, José "El mariscal Pardo de Cela", Galicia Histórica, 3 (1901), págs. 146163. 